\title{
A CANÇÃO NO LIVRO DIDÁTICO DE PORTUGUÊS: UMA DISCUSSÃO BASEADA NO LETRAMENTO LITEROMUSICAL
}

\author{
Jaqueline Silva Moreto Cabral* \\ Yuri Batista* \\ Eduardo Lopes Piris**
}

RESUMO: A preocupação em formar indivíduos competentes e autônomos, capazes de atuar nos diferentes campos e ocupar diversas posições frente aos discursos correntes na sociedade, tem colaborado para o surgimento de pesquisas voltadas ao ensino que privilegie práticas de letramento. A partir dessas considerações, esse artigo tem como objetivo discorrer sobre o conceito de letramento junto às práticas sociais, refletindo acerca das possibilidades do letramento literomusical na escola. Para este fim, propomos a análise do corpus constituído a partir das atividades sobre o gênero discursivo canção apresentadas por uma coleção didática de língua portuguesa para os anos finais do ensino fundamental, a saber, Português: Linguagens, aprovada pelo PNLD/2017 e adotada pelas escolas da rede pública municipal de Pinheiros/ES. De modo geral, a reflexão fundamenta-se nos conceitos de letramento (SOARES, 2000 [1998]), letramentos múltiplos (ROJO, 2009), letramento literomusical (COELHO DE SOUZA, 2014; 2015). Por sua vez, a análise do livro didático e das canções didatizadas apoia-se na perspectiva dialógica da linguagem (VOLOCHINOV, 2017 [1929]) e na concepção de gêneros do discurso (BAKHTIN, 2016 [1952-1953]). Os resultados alcançados indicam que a canção como objeto de ensino no livro didático não favorece o letramento literomusical, pois negligencia a linguagem musical e as práticas sociais que envolvem o gênero canção, limitando a canção a uma tarefa escolar tradicional.

PALAVRAS-CHAVE: Canção; Gênero do discurso; Livro didático; Letramento literomusical.

\section{Introdução}

A vida no mundo contemporâneo tem exigido de cidadãs e cidadãos a sua circulação nos mais variados campos da atividade humana, o que, em termos educacionais, demanda das instituições de ensino a abordagem da pluralidade de contextos de interação, de

\footnotetext{
* Mestre em Letras: Linguagens e Representações pela Universidade Estadual de Santa Cruz (Uesc). Vinculada ao grupo de pesquisa Estudos de Linguagem, Argumentação e Discurso (ELAD/CNPq).

** Mestre em Letras: Linguagens e representações pela Universidade Estadual de Santa Cruz (Uesc). Doutorando em Filologia e Língua Portuguesa pela Universidade de São Paulo (Usp). Bolsista FAPESP e em regime de cotutela com a Université de Paris- França. Pesquisador vinculado ao grupo de pesquisa DIÁLOGO-Usp.

*** Doutor em Letras pela Universidade de São Paulo (Usp). Realizou estágio pós-doutoral na Universidade Federal de São Carlos (UFSCar) e na Universidade de Buenos Aires (Uba). Docente da Universidade Estadual de Santa Cruz (Uesc).
} 
formas de uso da linguagem e de práticas sociais. Por esse motivo, são relevantes os esforços acadêmicos e pedagógicos mobilizados em torno do aprimoramento das práticas de leitura e escrita em suas múltiplas situações de uso e interação.

Desse modo, o termo letramento surge nos contextos escolares considerando a necessidade de estudantes aprimorarem suas capacidades de intervenção social por meio da linguagem, de compreensão de suas representações, de reconhecimento de fatores de construção dos discursos e de constituição dos sentidos, para que a língua seja significativa diante de suas "necessidades, valores e práticas sociais" (SOARES, 2000, p. 72). A função da escola tem sido reforçada, nas palavras de Ângela Kleiman (1995), como uma das mais importantes agências de letramento, ou seja, aquela sobre a qual recai o título de maior responsável por transformar e construir a criticidade do indivíduo. Ela possibilita ao estudante explorar outras facetas do mundo, sejam públicas, institucionais, midiáticas ou tecnológicas, de maneira a produzir "consciência do caráter de diferentes tipos de fala (e de escrita) e da sutileza de significados em contextos diferentes" (STREET, 2014, p. 39), que emolduram e fazem parte de sua vida.

São linguagens com propósitos distintos e que vão construindo significados por meio da associação com sons, imagens e outros meios semióticos que revolucionam o agir social. É por isso que existem diversas práticas de letramento conforme as situações de comunicação. A esse respeito, Street (2014) fala, inclusive, sobre a importante e complexa tarefa de desenvolver estratégias de letramento às variadas necessidades de uso da leitura e escrita nessa sociedade.

E qual a relação entre letramento literomusical e livro didático (LD) nesse estudo? A canção é um gênero discursivo que compreende em sua composição tanto a materialidade verbal (letra) quanto a musical, integra o convívio social não só dos estudantes, mas se faz presente noutras esferas, haja vista que traduz valores e comportamentos construídos historicamente. Para Vieira, Silva e Alencar (2012), trata-se de um gênero multissemiótico, pois o sentido não se constitui apenas no material linguístico, na linguagem verbal. Sua inserção no contexto escolar e no livro didático abre espaço para o letramento literomusical - conforme acepção de Coelho de Souza (2014) -, uma possibilidade do letrar frente à 
incontestável presença do gênero canção nas práticas sociais. O LD auxilia o professor no ambiente escolar e é reconhecido como material importante no processo de ensino, exercendo grande influência sobre o trabalho dos docentes, como salienta Munakata (2002). Acontece que a produção desse material didático, segundo Calissi (2005), sofre interferência da indústria cultural e das apreciações valorativas não só de determinada época, mas também de autoria, o que de certo modo implica no agir do professor.

Dessa maneira, apresentamos, neste artigo, reflexões acerca de como o gênero canção tem sido apresentado no livro didático e como nossas constatações podem favorecer o desenvolvimento do letramento literomusical nos educandos. Para isso, o artigo discorre sobre os postulados teóricos de Kleiman (1995), Soares (2000 [1998]) e Street (2014), para situar as ideias centrais do letramento, bem como aos trabalhos de Coelho de Souza (2014), para tratar do letramento literomusical, e de Munakata (2002) e Calissi (2005), para tratar do livro didático. Para ilustrar o problema apontado, procedemos à análise de três, das nove, atividades em torno do gênero canção propostas pela coleção didática Português Linguagens, aprovada pelo PNLD/2017 e adotada pelas escolas públicas do município de Pinheiros, Espírito Santo, Brasil.

\section{Letramento, letramentos múltiplos e letramento literomusical}

Segundo Magda Soares (2000 [1998]), o letramento surgiu do próprio processo de alfabetização, e foi progredindo para além do ato de tão somente codificar e decodificar a linguagem escrita, superando o conceito de alfabetizado funcional. De acordo com a referida autora, assim como para Kleiman (1995), apesar da associação, há que se considerar uma importante diferença entre ser alfabetizado e ser letrado, pois o princípio do letramento está na participação do indivíduo junto às práticas sociais, de forma que esse consiga fazer o uso da leitura e escrita em situações corriqueiras da vida.

Contudo, mesmo que diversos letramentos sejam praticados pela e na sociedade, de acordo com Street (2014), uma variedade específica foi hierarquizada de modo que se tornou legitimada em relação às outras formas realizadas na rua e no convívio familiar, por 
exemplo. Assim, fora difundido nas instituições escolares que o desenvolvimento do indivíduo, sua identidade, posição e "seu poder na sociedade fica associado ao tipo e nível de letramento" (STREET, 2014, p. 125) por esse adquirido. Para tanto, Street (2014) fala sobre um modelo autônomo de letramento no qual se pode observar:

[...] o distanciamento entre língua e sujeitos - as maneiras como a língua é tratada como se fosse uma coisa, distanciada tanto do professor quanto do aluno e impondo sobre eles regras e exigências externas, como se não passassem de receptores passivos; usos "metalinguísticos" - as maneiras como os processos sociais de leitura e escrita são referenciados e lexicalizados dentro de uma voz pedagógica como se fossem competências independentes e neutras, e não carregadas de significação para as relações de poder e para a ideologia; "privilegiamento" [...]. (STREET, 2014, p. 129-130, grifos do autor)

Retornando à concepção do termo letramento, para Kleiman (1995), esse nasceu da necessidade de formar leitores proficientes, os quais constroem os sentidos dos textos ao interagirem com esses, uma vez que é na relação desses textos com situações rotineiras e que exigem seu uso, que os mesmos adquirem significação para o indivíduo. Logo, a linguagem constrói sentido da relação com as experiências vividas e por meio da contextualização. É possível associarmos tal pensamento à concepção bakhtiniana de que a língua só é significativa, quando em situações concretas, reais de uso, em correlação direta com a cultura, a história, as ideologias, elementos que vão ao encontro do que Volóchinov (2017) trata por contexto extralinguístico.

Soares (2000 [1998]) sugere que o letramento consiste de um grande número de diferentes habilidades, competências cognitivas e metacognitivas, aplicadas a um vasto conjunto de materiais de leitura e gêneros de escrita, sendo esses usados e praticados em diferentes contextos sociais. Conforme a autora, sua definição é uma versão da palavra literacy, etimologicamente, provinda do latim littera (letra), com o sufixo -cy, que vem a denotar qualidade, condição, estado, fato de ser. 
É por isso que alguém letrado não só decodifica códigos, como se transforma, se supera nos aspectos social, cultural, cognitivo, linguístico, podendo corresponder às inúmeras demandas e exigências que emergem da vida em sociedade. Soares reforça a relação do mesmo junto às práticas sociais:

[...] letramento é o que as pessoas fazem com as habilidades de leitura e de escrita, em um contexto específico, e como essas habilidades se relacionam com as necessidades, valores e práticas sociais. Em outras palavras, [...] é o conjunto de práticas sociais ligadas à leitura e à escrita em que os indivíduos se envolvem em seu contexto social. (SOARES [1998], 2000, p. 72)

A linguagem verbal não é única para representarmos o mundo e construir significados acerca da nossa realidade. Em meio a tantas mudanças sociais, numa contemporaneidade em que as fronteiras que antes delimitavam distinções e distâncias são cotidianamente diluídas, a leitura, a escrita e demais formas de linguagem também são afetadas. Consequentemente, o conceito de letramento também foi influenciado, tendo seu campo expandido. Estamos inseridos em esferas e campos em que circulam diversas práticas sociais de uso da linguagem, desde as mais complexas, até as consideradas mais simples e corriqueiras. Segundo Rojo (2009), isso colaborou para que o termo adquirisse um sentido plural, o de letramentos múltiplos. E como defini-los?

Os letramentos múltiplos são decorrem das inúmeras formas de uso da linguagem em nosso dia a dia. Abarcam desde a cultura escolar, até a trazida pelo aluno, ou seja, suas experiências, seu conhecimento prévio de mundo. Portanto, as práticas de ensino precisam preparar o aluno para que esse esteja apto a circular entre as práticas sociais, dominando ambos os suportes. Desse modo, se fará dele um protagonista, alguém que tenha voz social, postura crítica e participativa, capaz de num texto "desvelar suas finalidades, intenções, ideologias" (ROJO, 2009, p. 120).

Partindo dessa premissa, de que estamos sujeitos a uma multiplicidade de gêneros e a várias situações de uso da linguagem, compreende-se que é natural nos envolvermos em diferentes letramentos, pois "não existe apenas um único tipo de práticas letradas" (COELHO DE SOUZA, 2014, p. 87). Por isso, pretende-se aqui refletir e conceituar uma 
categoria de letramento a partir de um gênero no qual se percebe o entrecruzar do verbal, do melódico e do rítmico, o literomusical, o qual envolve práticas sociais cuja canção, por exemplo, é representante e medeia as (inter)ações entre os participantes.

Como já faz parte da essência do ser humano, não é difícil citar situações em que a música promova (inter)ações: ao se tocar um instrumento; ouvir ou cantar o hino de seu time; entoar um cântico na igreja; dançar e outras. Pensando essas práticas, o que elas têm em comum? São situadas, concretas e tiveram músicas, canções, trechos ou outro gênero composto por letra e melodia vinculando a participação dos e entre indivíduos. Para Coelho de Souza (2014, p. 112), somos socializados através dessas práticas, mas nem sempre correspondemos às suas expectativas, uma vez que:

[...] um posicionamento crítico em relação aos discursos que se constroem a partir dela requer um conjunto de habilidades e competências distinto que engloba, por exemplo, um entendimento mais aprofundado das manifestações musicais e o reconhecimento dos seus contextos de produção, circulação e recepção [...].

Como já fora dito, a definição de letramento se expandiu. De acordo com Kleiman e Grande (2015), a prática social é seu objeto de estudo e a partir dessa noção que Coelho de Souza (2014, p. 112) propõe que o letramento literomusical seja entendido como:

[...] o estado ou condição daquele que, por construir e refletir sobre os sentidos de uma canção a partir de suas duas linguagens constitutivas (verbal e musical) e da sua articulação e por reconhecer o que representa para a comunidade musical a ela relacionada, participa das práticas sociais e dos discursos que se constroem a partir da canção e posiciona-se criticamente em relação a ela. Isso envolve reconhecer e interpretar as ações que estão sendo mediadas pela canção e, nessa interpretação, compreender a interlocução projetada e os valores a ela associados.

A canção, conforme Costa (2007) destaca, é um gênero de caráter intersemiótico, formado por duas interfaces (a verbal e a musical) que devem ser mutuamente consideradas, uma vez que se complementam e conferem ao gênero sua singularidade. Portanto, Coelho de Souza (2014) acredita que os sentidos que emergem da letra, das palavras e ver- 
sos da canção vêm da relação de seus recursos expressivos (linguísticos, poéticos ou literários) com os diferentes elementos musicais (melodia, ritmo, performance, etc.), os quais articulados constituem o que ele chama de efeitos de sentido literomusicais.

Assim, para ser reconhecido enquanto letrado literomusicalmente, o indivíduo deve interagir em práticas sociais mediadas pela canção ou outro gênero verbomusical, sendo capaz de depreender as camadas de sentido que se articulam nas distintas dimensões linguageiras constitutivas de tais gêneros, pois "na canção, texto e melodia são duas materialidades imbricadas" (COSTA, 2007, p. 113). Os efeitos de sentido literomusicais são, portanto, resultantes do entrecruzamento dessas duas linguagens materializadas e que evocam a melodia, o ritmo, os arranjos, associados às palavras, à letra como um todo.

Apoiando-nos no que disse Coelho de Souza (2014), com fins de favorecer o desenvolvimento do letramento literomusical dos estudantes, poderíamos sugerir que encaminhamentos didáticos com a canção sejam desenvolvidos em três níveis, a saber: i) no primeiro nível os alunos se deteriam mais atentamente à letra e às possibilidades interpretativas que ela sugere frente aos contextos de sua produção e de sua circulação, com especificidade ao contexto de interlocução dos educandos; ii) o segundo nível permitiria que os alunos se debruçassem na materialidade musical e, portanto, fossem capazes de observar questões relacionadas aos tipos de instrumentos musicais utilizados, os efeitos rítmicos e melódicos que o arranjo musical evoca, etc; iii) enquanto o terceiro nível, por fim, se ocuparia de tornar evidente que, na combinação dessas diferentes materialidades de linguagem, existe um efeito de sentidos singularmente perceptível na sua inter-relação.

Dentro dessas considerações, daremos prosseguimento à nossa discussão, destacando a forma com que o desenvolvimento do letramento literomusical se articula no livro didático. Para esse fim, dispomos, a seguir, nossas análises das propostas de didatização com o gênero canção na coleção Português: Linguagens (2015), utilizada nas escolas de Pinheiros (ES). 


\section{O livro didático favorece o letramento literomusical?}

Considerando os pontos levantados até aqui, passamos à análise do corpus, composto de três atividades didáticas em torno da canção presentes no livro didático de língua portuguesa Português: Linguagens, dirigido para os anos finais do ensino fundamental. Buscamos observar se esse material didático contribui, junto a docentes e discentes, para um trabalho com vistas ao desenvolvimento do letramento literomusical. Além disso, usamos esse momento de nossa trajetória para também pensar direcionamentos que possam ajudar docentes a desenvolvê-lo em suas rotinas pedagógicas.

A coleção didática Português: Linguagens (2015), de autoria de William Roberto Cereja e Thereza Cochar Magalhães, é composta de quatro volumes, destinados aos anos finais do ensino fundamental ( $6^{\circ}$ ao $9^{\circ}$ anos). Foi aprovada e validada pelo Programa Nacional do Livro Didático no triênio de 2017-2019 e adotada no município de Pinheiros/ES com o total de 1.2811 exemplares adquiridos.

Figura 1 - Capa de Português: Linguagens (2015), 6o ano

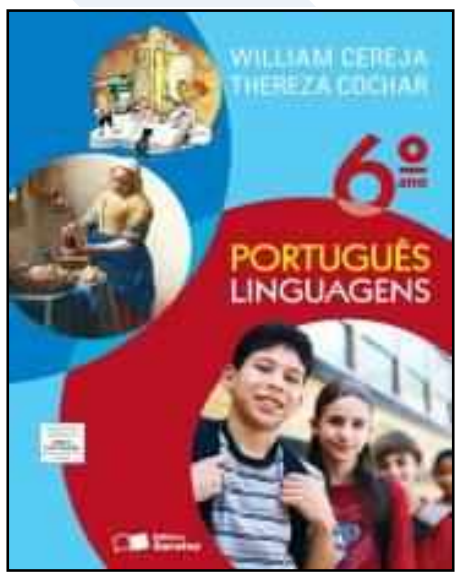

Fonte: Guia do PNLD/2017 (BRASIL, 2016)

\footnotetext{
${ }^{1}$ Resultado fornecido pelo PDDE Interativo, ferramenta de apoio à gestão escolar desenvolvida pelo Ministério
} da Educação em parceria com as secretarias estaduais e municipais. 
Cada volume, no aspecto geral, se organiza em 4 unidades temáticas, com 3 capítulos, totalizando 12 capítulos por volume. E as atividades, cujas canções foram didatizadas, correspondem ao total de 9 ocorrências, distribuídas da seguinte maneira nos quatro volumes da coleção:

Quadro 1 - Ocorrências de canções na coleção Português - Linguagens

\begin{tabular}{|c|c|l|}
\hline Ano & $\begin{array}{c}\text { Número } \\
\text { de ocorrências }\end{array}$ & \multicolumn{1}{c|}{ Títulos e autores das canções didatizadas } \\
\hline $6^{\circ}$ ano & 2 & $\begin{array}{l}\text { 1- A formiga, de Vinicius de Morais e Paulo Soledade } \\
\text { 2- Do it, de Lenine e Ivan Santos }\end{array}$ \\
\hline $7^{\circ}$ ano & 3 & $\begin{array}{l}\text { 1- Vermelho, de Vanessa da Mata } \\
\text { 2- A ordem das árvores, de Tulipa Ruiz } \\
\text { 3- Sou volúvel, de Arnaldo Antunes }\end{array}$ \\
\hline $8^{\circ}$ ano & 2 & $\begin{array}{l}\text { 1- Minha palhoça, de J. Cascata } \\
\text { 2- Emília, de Pato Fu }\end{array}$ \\
\hline $9^{\circ}$ ano & 2 & $\begin{array}{l}\text { 1- Chega de saudade, de Vinícius de Morais } \\
\text { 2- Pra fazer o sol nascer, de Gilberto Gil }\end{array}$ \\
\hline
\end{tabular}

Fonte: elaboração própria com base na coleção Português - Linguagens

Primeiramente, antecipamos não ser nosso intuito meramente observar as lacunas com a canção no material didático em questão, mas também refletir a partir daí como é possível orientar o trabalho docente para o letramento literomusical, utilizando o livro didático. Sabemos que nenhum material pode suprir plenamente as demandas individuais de cada realidade escolar, mas temos de ser críticos em relação ao conhecimento produzido e que circula no espaço educacional, de modo que seja possível revisar e ressignificar as práticas vigentes à luz dos saberes acadêmicos.

Para Rojo (2009), o LD, estando no lugar de suporte pedagógico e visando ao desenvolvimento do educando diante das inovações do mundo tecnológico e do mercado de trabalho, deve apresentar em suas propostas e nos seus referenciais teóricos a concepção de ensino pautada no domínio de letramentos múltiplos. Desse modo, ao considerarmos que em torno da canção orbita uma modalidade específica de letramento, convém ressaltar que a coleção didática em análise deixa de associar a linguagem verbal e a linguagem musical, ambas constitutivas do gênero canção. Os resultados apontados por Costa $(2003 ; 2007)$ 
repetem-se aqui, pois notamos nas atividades uma valorização do estudo da letra em detrimento dos componentes da linguagem verbal e, sobretudo, na relação intrínseca entre os sentidos construídos juntamente pelas duas linguagens, enfim pela palavra cantada. E, a esse respeito, Coelho de Souza (2014, p. 133) diz que

[...] a canção é tratada como um texto verbal a ser analisado através de perguntas, principalmente de compreensão oral ou leitura, ou como um objeto artístico a ser fruído, sem orientação sobre como apreciá-la. Em outras palavras, o enfoque dado é no ensino de aspectos linguísticos, ou seja, por meio da canção, em detrimento de uma abordagem pedagógica que leve em consideração características do gênero e seus efeitos estéticos. Acredito que a principal causa para que isso aconteça seja o fato de que o estudo da letra é quase sempre priorizado e desvinculado da linguagem musical [...].

A esse entrever, das nove canções didatizadas na Português: Linguagens (2015), a Minha palhoça, como aponta a figura, foi selecionada pelos autores para o estudo de flexão de verbos. A didatização aqui não destaca a canção em sua genericidade ou sua constituição linguageira, sequer mencionando que se trata desse gênero, o que delega ao professor e aos alunos o papel de reconhecer e identificar suas características e as linguagens que a constitui. É ausente uma preocupação em explorar os desdobramentos da linguagem verbal e musical, também não se percebe qualquer orientação para a audição da mesma. Distanciouse de questões singulares às modalidades de linguagem imbricadas nesse gênero, observase um destaque apenas para um trabalho com aspectos gramaticais da língua. Dessa maneira, tem-se a canção como uma espécie de pretexto para o ensino gramatical.

Observa-se ainda que se trata somente de um "trecho da canção" e, portanto, um outro ponto que acaba por interferir nesse tipo de trabalho: a fragmentação. Logo, a atividade não só negligencia a composição verbomusical do gênero, como também a compreensão dos aspectos externos a linguagem, nos quais se envolve seu contexto de circulação e produção. Portanto, a plasticidade e a singularidade que a compõem a canção são postas em segundo plano, e, quando propostas fora de sua integralidade discursiva, perdem as características que as ligavam à realidade à qual pertencem.

Figura 2 - Atividade em torno da canção "Minha palhoça", $8^{\circ}$ ano 


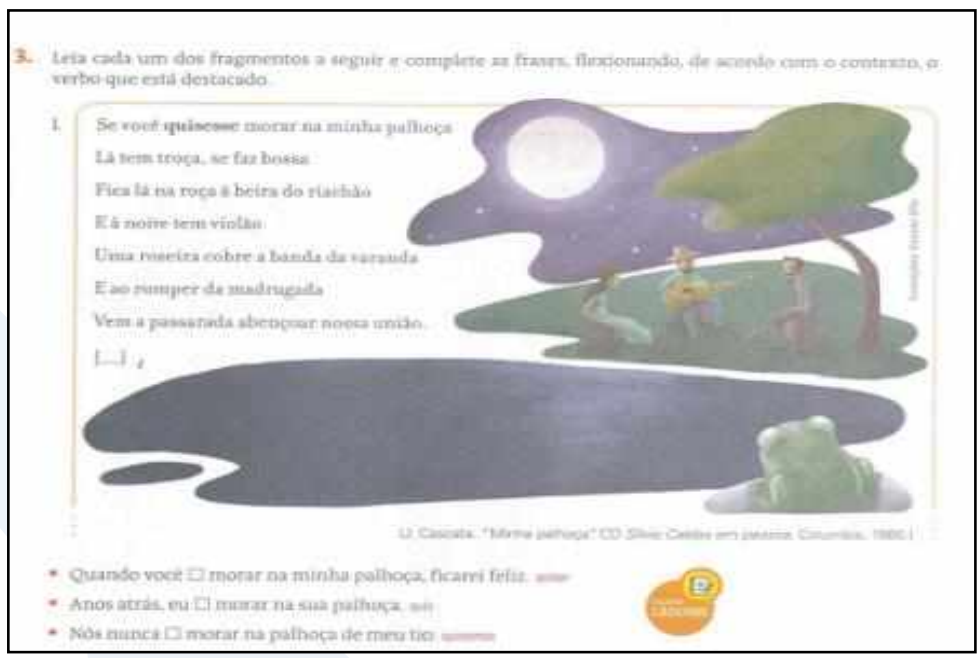

Fonte: Cereja \& Magalhães (2015, p. 55)

Continuando nossa análise, para Coelho de Souza (2014), o letrado literomusicalmente compreende que o compositor é alguém que pertence a uma comunidade musical e carrega consigo valores próprios que o representam. Inclusive, o ouvinte que se identifica com seu comportamento e visão de mundo, passa a compartilhar o seu jeito de se expressar e suas ideologias, pois:

Cada um desses grupos é visto de maneira diferente pelos que não pertencem a ele, tendo assim valores agregados distintos, os quais são geralmente associados tanto ao gênero musical em si quanto aos participantes de sua comunidade musical, gerando estereótipos que podem transcender épocas e locais. (COELHO DE SOUZA, 2014, p. 122)

Dessa forma, ao se trabalhar, numa abordagem literomusical, se almeja suscitar o posicionamento crítico dos estudantes, os quais poderão levantar inferências condizentes à situação de interlocução, com perguntas como: Quem enuncia na canção? Para quê e o que motivou o seu dizer? De onde ele se posiciona para pôr em prática o seu dizer? Quando e sob que contexto? Com qual finalidade? Questões dessa natureza conduzem e norteiam o aluno quanto aos usos sociais da canção nas condições reais em que circula a linguagem.

Figura 3 - Atividade em torno da canção "Chega de saudade", $9^{\circ}$ ano 


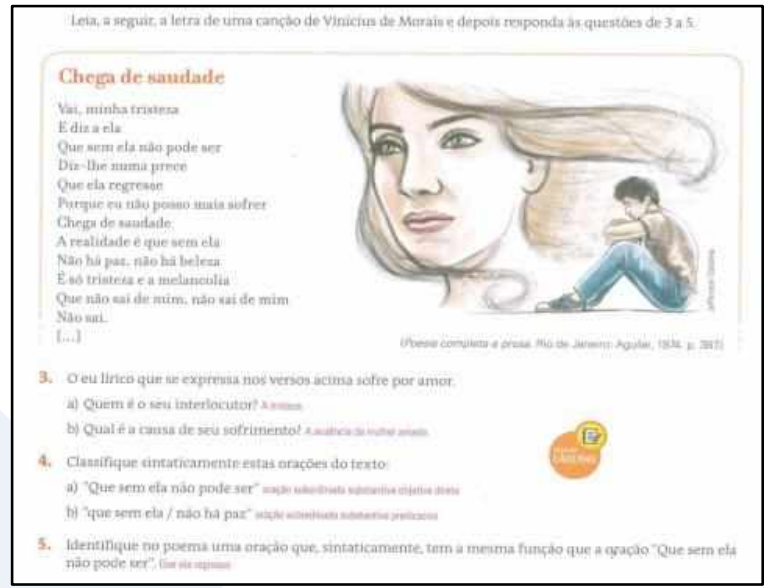

Fonte: Cereja \& Magalhães (2015, p. 22)

Na didatização proposta em torno de Chega de saudade, existe um encaminhamento para se trabalhar nesse aspecto, especificamente na questão 3. Nessas atividades, a materialidade musical não tem, mais uma vez, visibilidade. Temos a dimensão verbal explorada, ainda que com a presença de fragmentação.

Nota-se, ainda, que as atividades conduzem a uma percepção confusa, frente aos alunos. No início da proposta, apontam para o trabalho com uma canção, contudo, na questão 5, sugere-se tratar de um poema, um gênero distinto, mas que compartilha aspectos estilísticos e composicionais com o gênero canção (o lirismo, a versificação, o ritmo, a rima, etc.). O equívoco aqui é condizente com o pouco espaço dado à percepção das singularidades nos usos sociais que configuram o emprego de cada gênero. Esses usos a que nos referimos, variam conforme a esfera e os propósitos em que o gênero medeia as práticas de linguagem, à luz do que afirma Bakhtin (2016 [1952-1953). Por isso, Coelho de Souza (2014, p. 122) reforça que:

[...] torna-se relevante abordar em sala de aula o (re)conhecimento dos usos sociais, dos contextos de produção e de recepção [...]. Nessa mesma linha, também se torna relevante debater com os alunos os usos, funções sociais e valores atribuídos ao gênero [...]. 
Ao analisar as atividades, não identificamos a preocupação em se trabalhar tais aspectos, nos quais o aluno pudesse relacionar o uso da canção e sua função social para além do contexto escolar. Tal lacuna seria preenchida pela intervenção docente no âmbito de sua prática, cabendo-lhe, por sua vez, explorar as distinções entre os gêneros e, ainda, propiciar procurar ampliar a compreensão dos alunos aos aspectos musicais, traço não enfocado pela coleção analisada.

As canções pertencentes à MPB foram constantes na coleção. Esse gênero musical atingiu grande representatividade no país, ao lado do Rock, pois ambos assumiram importante função comunicativa na sociedade, nos anos 60 e 80. Coelho de Souza (2014) acredita ser esse um dos critérios para se pensar o ensino por meio da canção, a fim de que seja uma prática significativa aos discentes. Nesse sentido, os autores da coleção poderiam tê-las explorado com questões que remetessem à sua popularidade ou ter criado boxes em que expusessem sua origem e seu contexto sócio-histórico de produção.

De acordo o MTS (2014), a música é formada por silêncios e por sons, sendo estes últimos analisados conforme duração, altura, timbre e a intensidade. Essas características permitem dizer se o som é: (1) longo, médio, curto; (2) grave, médio, agudo; (3) forte, fraco, médio. Aqui começamos a ressaltar os sons, os silêncios e suas formas de percepção para explanar mais detidamente como a linguagem musical é negligenciada nas propostas de atividades com canções. A dimensão musical que compõe, entre outros exemplos, o gênero canção, carece de melhor espaço para ser percebida e analisada nos livros didáticos enquanto materialidade que produz efetivamente sentidos. Em sua caracterização a linguagem musical pode ser percebida quanto à sua expressão e à sua forma. Para tanto, vamos observar no Quadro 2:

Quadro 2- Instrumentos musicais

\begin{tabular}{|c|c|c|c|c|c|}
\hline Piano & Cordas & Guitarra & Bateria & Gaita & Teclado \\
\hline Baixo & Pandeiro & Flauta & Sax & Clarinete & Triângulo \\
\hline
\end{tabular}

Fonte: elaboração baseada em Coelho de Souza (2014) 
O Quadro 2 apresenta alguns instrumentos que comumente são identificados durante a audição de uma canção. A coleção didática Português - Linguagens em momento algum direciona qualquer tipo de percepção dos diferentes instrumentos musicais e suas projeções de sentido que podem compor a linguagem musical, por exemplo. Após uma escuta atenta, de acordo com Coelho de Souza (2014), a compreensão é sempre possível, o que varia é o nível de percepção de cada aluno e o conhecimento musical que eles possuem. Quando se tem margem para pensar os tipos de instrumentos que a envolvem, pode-se levar o educando a reconhecer aqueles com os quais não se teve a oportunidade de socialização, mesmo que sejam típicos em nosso país, como o pandeiro, por exemplo. Essa abertura pode incitá-los a falar de outro(s) instrumento(s) e quem sabe, motivar quem saiba tocá-lo(s) a participar da atividade, reproduzindo a melodia em sala.

Repetindo, quando enfatizada, a materialidade musical pode contribuir para que os estudantes aperfeiçoem sua audição, ampliem seu repertório musical e cultural, e claro, se tornem ouvintes mais atentos no que tange o discurso literomusical. Sobre a dimensão material, Coelho de Souza (2014, p. 69) faz uma interessante comparação:

[...] os materiais sonoros estão para a música assim como o sistema fonológico está para a língua: mesmo que juntemos um grupo de sons a ponto de formar palavras, enquanto as mesmas não forem dotadas de intencionalidade discursiva e estruturadas na forma de um enunciado, elas não pertencerão ao âmbito discursivo da língua.

Se os acordes, uma figura rítmica, um intervalo, são todos aplicados numa canção com um objetivo, uma intenção, logo, a expressão musical não compõe uma obra por acaso. Essa é responsável por estimular impressões no ouvinte, enquanto interlocutor participante do processo enunciativo. Se a Português: linguagens (2015) desejasse contemplar esse aspecto oriundo da linguagem musical da canção, teria proposto questões do tipo: Que sensações a canção provocou em você? Se trata de uma melodia leve ou pesada? Vibrante ou tranquila? Em que situações você a ouviria? O que ela te faz lembrar? Em que práticas e esferas ela é comum? Não é à toa que o uso da expressão clima da canção é associada a essa dimensão. 
Outra dimensão, que é a forma, pode levar a reconhecer o uso de repetições ou de variações nos padrões melódicos (timbre), de modo que consigam dividir uma canção em partes e, a partir disso, compreender melhor seu desenvolvimento. Se tentarmos considerar as atividades das canções em análise, concluiremos que não houve essa pretensão, por parte dos autores. De fato, essa possibilidade foi descartada quando algumas canções foram fragmentadas, pois não só os sentidos produzidos pela materialidade verbal (letra) são comprometidos, mas também os que se estruturam a partir da materialidade sonora (melodia), como já pontuamos. Vejamos o Quadro 3:

Quadro 3 - Performance musical

\begin{tabular}{|c|c|c|c|c|}
\hline Andamento & Clima & Vocal & Partes & Algo interessante \\
\hline $\begin{array}{c}\text { (rápido, médio, } \\
\text { lento...) }\end{array}$ & $\begin{array}{c}\text { (alegre, triste, vi- } \\
\text { brante...) }\end{array}$ & $\begin{array}{c}\text { (suave, gritado, } \\
\text { vibrato...) }\end{array}$ & $\begin{array}{c}\text { (A/ A-B/ } \\
\text { A-B-C/...) }\end{array}$ & \\
\hline
\end{tabular}

Fonte: Elaboração a partir de Coelho de Souza (2014)

O referido quadro se propõe a inspirar propostas que possam pensar a forma como a canção foi estruturada e como o intérprete executou sua performance. Coelho de Souza (2014) pontua que essa percepção pode ser estimulada por meio de algumas perguntas, como: Quais sensações a canção lhe transmite? Você a dividiria em partes? Como está sendo cantada? Isso é possível por causa dos materiais sonoros? A performance dedicada lhe remeteria a dançar, a relaxar?

Figura 4 - Trecho das atividades com a canção "Do it"

4. Como os poemas, as letras de cançào geraimente exploram o ritmo e a sonoridade das palavras. Quanto a sonoridade, que efeito resulta do empre

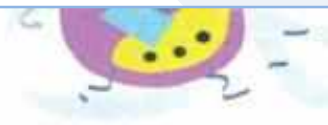
go de formas verbais no imperativo no final dos

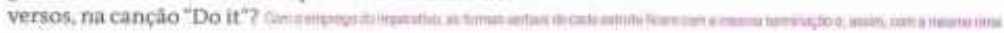

5. Oa verbos têm um papel destacado ma letra de cançio. Considerando que o titulo dela, "Do it", em inglès. significa "Fạa isso", responda: For que os verbos uJ̃o fundamentais na construção desse texto?

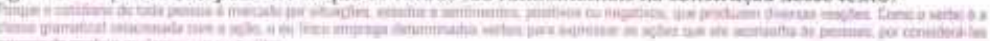

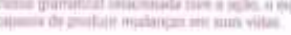

Fonte: Cereja \& Magalhães (2015, p. 245) 
$\mathrm{O}$ aspecto sonoridade foi brevemente mencionado na questão 4, de Do it, criando a perspectiva de que seria abordada, mas somente fizeram menção ao ritmo por trás da rima das palavras, quando seria uma oportunidade para explorar mais esse aspecto expressivo do literomusical. Na verdade, em se tratando de gêneros verbomusicais, é preciso considerar a linguagem musical associada à verbal para construção dos sentidos, uma vez que a relação conjunta de sentidos entre as duas linguagens caracteriza o enunciado verbomusical como um todo de sentido. O privilégio apenas do verbal, como foi a tendência constatada nas atividades propostas pela coleção, assim como o uso majoritário de alternativas como pretexto para o ensino de gramática, inviabiliza o desenvolvimento do letramento literomusical e acaba por "mutilar” o gênero em sua constituição intersemiótica.

Se houvesse a sugestão de desenvolver a audição, essa poderia ser estimulada por questões, como: Quem ouve esse gênero musical? Quem o ouvia? Quais compositores você conhece? A discografia lhe é familiar? Já houve regravação? Com essa última pergunta, o material proporia relações dialógicas, pois marcas de quando e onde foi produzida acabam por acompanhar as canções. E já que falamos nisso, o dialogismo, conforme Rojo (2015), esse é possível quando conseguimos reconhecer a intertextualidade como elemento constitutivo da linguagem. Esse pensar reitera junto aos alunos a natureza dialógica da linguagem, uma vez que as canções são enunciados produzidos em um determinado contexto extralinguístico e respondem a outros enunciados, como também esperam resposta de outros que ainda não foram proferidos, sendo esses pertencentes ao mesmo ou a outros gêneros como "um elo na cadeia da comunicação discursiva" (BAKHTIN, 2003 [1920-1923], p. 279).

Importante dizer que mesmo questões de compreensão oral ou leitura, não contribuirão para um trabalho significativo, se caso nas práticas pedagógicas, a canção seja tratada apenas numa abordagem transmissiva, em que o estudar a língua esteja associado a dar maior relevância a aspectos gramaticais, que muito já foram o foco de um ensino tradicionalista. Pelo contrário, conforme o Guia (BRASIL, 2016), nosso objetivo deve ser o de trabalhar o texto, os gêneros e também os usos linguísticos numa abordagem discursiva, 
através de "um viés sociointeracionista e com uma preocupação com as práticas de letramento" (BRASIL, 2016, p. 25). Então, as propostas deveriam sempre permitir aos alunos que se posicionassem diante a canção, pois "ler é (re)agir criticamente de acordo com a expectativa criada pelo gênero discursivo" (SCHLATTER, 2009, p. 13 apud COELHO DE SOUZA, 2014, p. 157).

Como pensamos na canção na perspectiva dos letramentos é esperado escolher aquela, segundo Coelho de Souza (2014), que possibilite trabalhar com outros gêneros discursivos com os quais ela mantenha relações, contudo não presenciamos isso nas atividades propostas por Português: Linguagens (2015). Tais atividades poderiam colaborar, como já colocado, para acionar o conhecimento prévio dos discentes que, segundo Rojo (2009), consiste em relacionar o que se irá aprender ao já construído, em termos bakhtinianos, tornar o contexto da prática e uso da linguagem em algo concreto, situado.

A coleção apresenta a seção "Trocando ideias", em que perguntas que despertassem impressões sobre os gêneros musicais, a origem das canções, quais ouvintes presumidos, que temáticas comuns, se são adeptos daquele estilo ou não poderiam ter sido propostas. Ou ainda, boxes informativos, leitura de textos bibliográficos sobre os intérpretes ou compositores, uma pesquisa histórica do gênero musical em questão, o acesso à reportagens sobre o estilo musical.

Estamos (re)discutindo práticas pedagógicas visando tratar das canções didatizadas pelo LD no cerne das práticas e funções sociais que elas medeiam. Assim, de acordo Coelho de Souza (2014), se pode criar subsídios para o desenvolvimento literomusical dos educandos. Não se pretende formar músicos, mas é preciso que professores e alunos sejam sensíveis à existência dessa outra interface do gênero canção. O objetivo é de que o aluno se posicione frente a ela, lançando não apenas um olhar linguístico, mas também, à sua própria maneira, um conhecimento musical (melodia, ritmo, harmonia, o arranjo/ performance, andamento), uma vez que gêneros verbomusicais têm seus efeitos de sentido assim articulados. Muito do que foi relatado nos leva a crer, a partir de Coelho de Souza (2014), que questões cujo gênero canção foi didatizado nos volumes da coleção Português: Linguagens 
(2015) não são um caminho que favoreça o desenvolvimento do letramento literomusical no contexto escolar.

\section{Algumas considerações finais}

A canção é uma prática de linguagem intersemiótica presente em distintas esferas da atividade humana. Nesse trabalho, buscamos enfatizar que, à guisa das teorias de letramento e, em específico do letramento literomusical, é necessário valorizar não somente os significados das palavras, o conteúdo dos versos ou da letra de uma canção. É preciso que sejam considerados os seus efeitos estéticos, expressivos, materiais, os quais implicam na forma como ela produz sentidos e pode ser apreciada por seus interlocutores e, no caso das esferas escolares, os sujeitos alunos. Desse modo, a canção necessita ser compreendida como um gênero que contempla não apenas os aspectos linguísticos, mas igualmente os musicais, sem os quais os sentidos que a constituem não podem ser depreendidos de forma integral.

Após a análise e discussão sobre as atividades didatizadas a partir do gênero canção na Português: Linguagens (2015), pudemos observar e pontuar que embora essa se faça presente como gênero, os livros analisados não fazem referência às duas modalidades de linguagem que a compõe e se considerarmos o que Coelho de Souza (2014) conceitua sobre a possibilidade de promoção do letramento literomusical dos alunos, percebemos que as atividades dessa coleção pouco cumprem esse objetivo. O fato de terem dado certa relevância somente à letra contribuiu para chegássemos a essa conclusão.

A presença da canção no LD nem sempre é expressiva, de modo que, quando proposta nos materiais didáticos, vê-se excluídos ou negligenciados aspectos, que, se enfatizados, podem contribuir para o que Rojo (2012) chama de aprendizagem significativa, face ao contexto situacional de interação. Portanto, as pesquisas devem avançar no intuito de fomentar discussões a respeito da materialidade musical da canção e de contribuir para que durante a produção de material didático os autores proponham que essa seja melhor trabalhada na esfera escolar. 
É necessário, contiguamente, que o professor assuma uma postura reflexiva com relação à sua prática pedagógica e direcione um outro olhar para o uso do livro didático. Dizemos isso, pois esses estão condicionados à metodologia do LD que, segundo Munakata (2002), acaba por orientar o dizer e o fazer no que condiz aos conteúdos transmitidos, às aulas e ao planejamento desses profissionais. Logo, o professor que deseja que seus alunos sejam letrados literomusicalmente, necessita conduzi-los a explorarem, de modo aprofundado, quais as manifestações e práticas sociais, qual o contexto de produção, de circulação e de recepção permeia a canção em estudo, por exemplo. Nesse sentido, o docente necessita, em muitas vezes, ir além dos conformes propostos pelo LD e se propor a engajar o gênero canção em sua integralidade, considerando as diferentes semioses que o constituem.

\title{
THE SONG IN PORTUGUESE LANGUAGE HANDBOOK: A DISCUSSION BASED ON LITEROMUSICAL LITERACY
}

\begin{abstract}
The concern in forming competent and autonomous individuals, capable of acting in different fields and occupying different positions in front of the current discourses in society, has contributed to the emergence of research aimed at teaching that privileges literacy practices. Based on these considerations, this article aims to discuss the concept of literacy in relation to social practices, reflecting on the possibilities of literomusical literacy at school. To this end, we propose the analysis of the corpus constituted from the activities on the song as discursive genre presented by the textbook collection of elementary school, Português: Linguagens, approved by PNLD/2017 and endorsed by the Pinheiros city educational network. In general, the reflection is based on the concepts of literacy (SOARES, 2000 [1998]), multiple literacy (ROJO, 2009), literomusical literacy (COELHO DE SOUZA, 2014; 2015). In turn, the analysis of the textbook and the didatized songs is based on the dialogical perspective of language (VOLOCHINOV, 2017 [1929]) and the conception of genres of discourse (BAKHTIN, 2016 [1952-1953]). The results achieved indicate that song as a teaching object in the textbook does not favor literomusical literacy, as it neglects musical language and social practices involving the song genre, limiting the song to a traditional school task.
\end{abstract}

KEYWORDS: Song. Genre of discourse. Textbook. Literomusical literacy.

\section{REFERÊNCIAS}

BAKHTIN, Mikhail. Os gêneros do discurso. Organização, tradução, posfácio e notas de Paulo Bezerra; notas de edição russa de Serguei Botcharov. São Paulo: Editora 34, 2016 [1952-1953].

. Estética da criação verbal. Introdução e tradução do russo Paulo Bezerra; prefácio à edição francesa Tzvetan Todorov. 4. ed. São Paulo: Martins Fontes, 2003 [1920-1923]. 
BRASIL, Ministério da Educação. Secretaria de Educação Fundamental. Guia de livros didáticos: PNLD 2017: língua portuguesa - Ensino fundamental anos finais. Brasília, DF: Ministério da Educação; Secretaria de Educação Básica, 2016.

CALISSI, Luciana. A música popular brasileira nos livros didáticos de história. In: Anais do XXIII simpósio nacional de história - ANPUH, Londrina, 2005. p. 1-8.

CEREJA, W.R.; MAGALHÃES T. C. Português: linguagens. $6^{\circ}$ ao $9^{\circ}$ anos. Manual do professor, São Paulo: Saraiva, 2015.

COELHO DE SOUZA, José Peixoto. Letra e música no ensino de português como lingua adicional: uma proposta de letramento literomusical. 2014.Tese (Doutorado em Linguística Aplicada), Porto Alegre: Universidade Federal do Rio Grande do Sul, 2014.

COSTA, Nélson Barros da. Canção popular e ensino de lingua materna: o gênero canção nos Parâmetros Curriculares de Língua Portuguesa. Linguagem em (Dis)curso, Tubarão, v. 4, n. 1, jul./dez., p. 9-36, 2003.

. As letras e a letra: o gênero canção na mídia literária. In: DIONÍSIO, Ângela Paiva; MACHADO, Anna Rachel; BEZERRA, Maria Auxiliadora (Org.). Gêneros textuais e ensino. Rio de Janeiro: Lucerna, p. 107-121, 2007.

KLEIMAN, Angela. Os significados do letramento: uma nova perspectiva sobre a prática social da escrita. Campinas: Mercado de Letras, 1995.

KLEIMAN, A.; GRANDE, Paula B. Intersecçoes entre a linguística aplicada e os estudos de letramento: desenhos transdisciplinares, éticos e críticos de pesquisa? Revista Matraga, v. 22, p. 11-30, 2015. Disponível em: http://www.publicações.uerj.br/index.php/matraga/article/view/17045

MTS. Método de teoria e solfejo com aplicação ao binário. Distribuído pela Congregação Cristã no Brasil. Rua Visconde de Parnaíba, no1616 - Anexo: Bloco G, CEP 03164-300. São Paulo, 2014.

MUNAKATA, Kazumi. Livro didático e formação do professor são incompativeis? In: CONGRESSO BRASILEIRO DE QUALIDADE NA EDUCAÇÃO: FORMAÇÃO DE PROFESSORES, 1, 2001, Brasília. Simpósios [do] Congresso Brasileiro de Qualidade na Educação: formação de professores. Marilda Almeida Marfan (Organizadora). Brasília: MEC; SEF, p. 89-94, 2002.

ROJO, Roxane. Letramentos múltiplos, escola e inclusão social. São Paulo: Parábola Editorial, 2009.

. Pedagogia dos multiletramentos: diversidade cultural e de linguagens na escola. In: ROJO, Roxane; MOURA, Eduardo (Org.). Multiletramentos na escola. São Paulo: Parábola Editorial, p. 11-31, 2012.

ROJO, R.; BARBOSA, Jacqueline. Hipermodernidade, multiletramentos e gêneros discursivos. São Paulo: Parábola Editorial, 2015. 
SOARES, Magda B. Letramento: um tema em três gêneros. Belo Horizonte: Autêntica, 2000 [1998].

STREET, Brian. Letramentos sociais: abordagens críticas do letramento no desenvolvimento, na etnografia e na educação. Tradução de Marcos Bagno. 1. ed. São Paulo: Parábola Editorial, 2014.

VIEIRA, Eliane A. P. ; SILVA, Flávia Danielle S.; ALENCAR, Maria Aparecida M. A canção: roda-viva. In: ROJO, Roxane; MOURA, Eduardo (Org.). Multiletramentos na escola. São Paulo: Parábola Editorial, 2012, p. 181-198.

VOLOCHINOV, Valentin. Marxismo e filosofia da linguagem: problemas fundamentais do método sociológico na ciência da linguagem. Tradução, notas e glossário de Sheila Grillo e Ekaterina Vólkova Américo; ensaio introdutório de Sheila Grillo. 1. ed. São Paulo: Editora 34, 2017 [1929].

Recebido em: 29/04/2020.

Aprovado em: 29/05/2020. 